\title{
Editorial \\ Defence
}

Associate Editor: John Catherall

The Editors are pleased to offer this opportunity for the associate editor for Defence to outline his domain, and seek contributions from potential authors.

Operational Research and defence have been entwined since birth of the discipline. While there had been isolated applications of scientific method to warfare at least as early as WWI, most notably in the work of Frederick Lanchester, the first stirrings of what we now regard as $O R$ occurred with regard to the operational use of radar technology in 1939. By the end of WWII, a number of simple but effective analytical methods were in use on both sides of the Atlantic, such as statistics and probability theory, ballistics, search and detection theory (including notable applications to convoy safety and Coastal Command operations) as well as Lanchester Theory.

Analysts working on defence issues today bring a wide range of $\mathrm{OR}$ techniques to bear on a rich palette of analytical challenges, some of them unique to the field. These range from "low level" topics such as equipment performance and optimum sensor mixes, through assessment of capability, force effectiveness and readiness, logistics and training to long-term balance of investment and policy issues. With the move towards more flexible, varied deployments to the world's trouble spots, the focus on logistics is increasing (to which the proposed use of contractors deployed on operations (GONDO) is adding a new dimension). Alongside these are the challenges of analysis in the cognitive domain, exemplified by the modelling of Command and Control (C2) and the understanding of new threats in a rapidly changing world with a complex and turbulent past, and of our increasingly networked environment (both electronic and human).

Many of the analytical challenges arising in the defence field involve numerous parameters and interactions, some of which are not amenable to quantitative analysis. Defence OR has, in the past, depended heavily on simulation models. Today, notwithstanding the appearance of new approaches for new problems, simulation continues to be very important, employing a wide variety of techniques from spreadsheets to wargaming and large time-stepping simulations. The increasing emphasis on the use of military forces in situations short of large-scale armed conflict (for which there are several portmanteau descriptions including Diplomatic/Military operations) has lead to a new generation of models which can represent multiple "sides", not necessarily combatant, with different aims, and where straightforward win/lose criteria may well be inappropriate. Gaming techniques, too, are being applied to issues outside the conventional military arena: for example, Davies (2003) describes an application of the RAND "Day after..." method to threats to critical infrastructure. Other simulation initiatives seek to explore the essence of complex behaviours by using techniques drawn from the complex systems world, including fractal analysis and cellular automata.

In attempting to assess what we should do and how, there is increasing emphasis on capability to achieve particular ends rather than simply on particular means such as equipment. This in turn requires analysts to take a more holistic view, devising metrics and means of aggregation not just from individual equipment to force level, 
but beyond, to embrace the overall political aims of an operation and their relation to the use of military force. Increasingly "soft", judgmental, methods are employed in these complex, and often little quantified, problems. For two recent examples, see Mitchell and Medhurst (2003), which describes an application to NBC capability, and the discussion of the problems of rigour and objectivity in assessment hierarchies by Mathieson (2001). Other aspects of nonquantitative analysis are exemplified by the use of influence diagram methods and social network analysis to explore potential future threats and means to control them.

One particular aspect of practical OR applied to defence is the use of analysts deployed on real operations and the post Cold War era has seen increased numbers of UK analysts in support of "front line" HQs. Some of this, echoing the spirit of the earliest days, has involved support to conventional operations, from initial planning to the gathering and analysis of data in support of "lessons learned". Increasingly, though, analysts are deployed in support of diplomatic/military operations. With the need to respond quickly, sometimes under arduous conditions, analysts are employing a wide range of alternative approaches and metrics, often aimed more at civil functioning than at military operations, to assess these missions. Two examples of this are described by Griffin (2000) and by Lambert (2000) (operations in Bosnia-Herzegovina) and by Neighbour et al (2002) (compliance assessment during Peace Support Operations in Kosovo).

The requirement for objective, evidence-based analysis has never been greater. There are a number of drivers. These include the rapid development and spread of new technologies, the downward pressure on defence budgets and the increasingly stringent requirement for justification for procurement decisions. The rich mixture of defence problems, some still seeking fully effective treatments, continues to be ideal territory for innovative ideas and applications in OR. Though, inevitably, some of the detail of work done for defence cannot appear in open publication, the techniques used, together with sufficient illustrative detail, very often can be brought before a wider audience. It is important that practitioners of OR in defence keep abreast of new developments; equally, it is important that they also report back any advances that they might have made in case those advances have wider applicability. OR Insight provides an ideal forum for the satisfaction of both of these aims and I keenly invite those working in the defence arena and to submit papers describing practical applications, which can be done via jcatherall@dstl.gov.uk.

\section{References}

Davies, S.J. (2003) Strategic gaming to support critical national infrastructure protection: a practitioner's view, OR Insight 16 (2), p4-1 1

Griffin S. (2000) Operational analysis in the frontline - a progressive environment, OR Insight 13 (2), p15-20

Lambert N. J. (2002) Measuring the success of the NATO operation in Bosnia and Herzegovina, 1995-2000, European Journal of Operational Research 140 (3), p459481

Mathieson G. (2001) Best practice for using assessment hierarchies in operational analysis - principles and practical experiences, OR Insight 14 (2), p3-13

Mitchell, I. M. and Medhurst J. (2003) Modelling enabling capabilities, OR Insight 16 (2), p20-27

Neighbour M. R., Bailey P., Hawthorn M., Lensing C., Robson H., Smith S. and Zimmerman B. (2002) Providing operational analysis to a peace support operation: the Kosovo experience, Journal of the Operational Research Society 53 (5), p523-543 